14.10

\title{
Влияние хлорида аммония на структуру наночастиц гидроксиапатита и пролиферативную активность мезенхимных стромальных клеток
}

\author{
( С И.П. Добровольская, ${ }^{1,2}$ К.В. Малафеев, ${ }^{1}$ Ю.А. Нащекина, ${ }^{1,4}$ И.А. Касаткин, ${ }^{3}$ Е.Н. Попова, ${ }^{2}$ В.Е. Юдин ${ }^{1,2}$ \\ ${ }^{1}$ Санкт-Петербургский политехнический университет Петра Великого, \\ 195251 Санкт-Петербург, Россия \\ ${ }^{2}$ Институт высокомолекулярных соединений РАН, \\ 199004 Санкт-Петербург, Россия \\ ${ }^{3}$ Санкт-Петербургский государственный университет, \\ 199034 Санкт-Петербург, Россия \\ ${ }^{4}$ Институт цитологии РАН, \\ 194064 Санкт-Петербург, Россия \\ e-mail: zair2@mail.ru
}

Поступило в Редакцию 21 января 2020 г.

В окончательной редакции 10 апреля 2020 г.

Принято к публикации 10 апреля 2020 г.

Получены наночастицы синтетического гидроксиапатита, содержащие кристаллы хлорида аммония. Методами рентгеновской дифракции, термогравиметрического анализа и БЭТ показано, что разложение кристаллов хлорида аммония в среде аргона происходит в интервале $T=220-270^{\circ} \mathrm{C}$. Обработка при $T=300^{\circ} \mathrm{C}$ приводит к термической стабильности наночастиц. Наличие хлорида аммония в культуральной среде существенно влияет на биосовместимость наночастиц, увеличение его содержания снижает пролиферативную активность мезенхимных стромальных клеток.

Ключевые слова: наночастицы, гидроксиапатит, хлорид аммония, структура, пролиферативная активность, стромальные клетки.

DOI: $10.21883 / J T F .2020 .09 .49696 .27-20$

\section{Введение}

Гидроксиапатит (ГА) используют в медицине, в частности в трансплантологии, при замене костных тканей, поврежденных в результате травм или болезней. Ортофосфаты кальция входят в состав костей, зубов, сухожилий, придавая им прочность и упругость. Ткани животных и человека включают до 70 mass\% ГА в виде наночастиц различной формы и размеров. ГА наряду с молекулами коллагена, а также клетками (остеобластами, остеоцитами, остеокластами идр.) включен в процессы рекомбинации ткани, необходимые для жизнедеятельности организма. Поэтому важной характеристикой материалов, используемых в клеточных технологиях и в тканевой инженерии, является их биосовместимость. Только отсутствие негативного влияния как самого материала, так и продуктов его биоразложения на адгезию и пролиферативную активность клеток позволяет успешно использовать синтетические материалы в составе матриц для тканевой инженерии. [1].

В связи с развитием тканевой инженерии, активно ведутся исследования по разработке способов получения и изучению свойств синтетического ГА [2,3]. Известно 11 иононезамещенных ортофосфатов кальция с молярным соотношением $\mathrm{Ca} / \mathrm{P}$ от 0.5 до 2.0 [4]. Наиболее широко используются фосфаты кальция из группы ГА. Наночастицы фосфатов кальция могут быть синтезированы различными способами: сухим и мокрым, гидротер- мальным, механохимическим, с использование микроволновых процессов, а также с применением микро- и наноэмульсионной технологии. Наиболее полно способы получения и свойства синтетического ГА описаны в работах [5,6]. В статье [7] обобщены методы синтеза кристаллов фосфатов кальция, определения их размеров от нано- до макроуровня. Особое внимание уделено изучению формы одно-, двух- и трехмерных частиц. Результаты исследования влияния термической обработки на структуру и свойства наночастиц синтетического и биологического ГА приведены в работе [3]. Методами рентгеновской дифракции, электронной просвечивающей микроскопии показано, что ГА, полученный методом осаждения, представляет собой порошок, состоящий из анизометричных частиц, продольный размер которых составляет 70-100 nm, а поперечный - 7-9 nm. Частицы состоят из кристаллитов с продольными размерами $22-24 \mathrm{~nm}$, поперечными - 8-10 nm. При температуре $600^{\circ} \mathrm{C}$ происходит рост кристаллитов, уменьшение объемной пористости и удельной поверхности. Синтетический ГА характеризуется меньшей термической устойчивостью по сравнению с ГА биологического происхождения.

Одним из наиболее распространенных методов получения синтетических наночастиц ГА является их осаждение из смеси водных растворов $\mathrm{CaCl}_{2}$ и $\left(\mathrm{NH}_{4}\right)_{2} \mathrm{HPO}_{4}$ [8], в качестве осадителя используют раствор аммиака $\left(\mathrm{NH}_{4} \mathrm{OH}\right)$. В результате реакции, кроме кристаллов ГА 
и воды, образуется хлористый аммоний $\mathrm{NH}_{4} \mathrm{Cl}$ - кристаллическое вещество, растворимое в воде, кристаллы которого при нагревании до $338^{\circ} \mathrm{C}$ распадается на $\mathrm{NH}_{3}$ и $\mathrm{HCl}$.

Поэтому целью настоящей работы являлось исследование структуры наночастиц синтетического ГА, полученного методом осаждения, изучение влияния ГА на пролиферативную активность мезенхимных стромальных клеток (CK).

\section{1. Экспериментальная часть}

Образцы наночастиц, содержащие ГА и хлорид аммония, получены в университете Сапиенза, Рим, Италия, методом синтеза, который описывается реакцией:

$$
\begin{aligned}
& 10 \mathrm{CaCl}_{2}+6\left(\mathrm{NH}_{4}\right)_{2} \mathrm{HPO}_{4}+8 \mathrm{NH}_{4} \mathrm{OH} \\
& \rightarrow \mathrm{Ca}_{10}\left(\mathrm{PO}_{4}\right)_{6}(\mathrm{OH})_{2}+20\left(\mathrm{NH}_{4}\right) \mathrm{Cl}+6 \mathrm{H}_{2} \mathrm{O} .
\end{aligned}
$$

Содержание хлорида аммония варьировалось от 20 до $\sim 40$ mass $\%$, что достигалось режимом отмывки реакционной смеси в деионизованной воде. Были получены образцы, содержащие 20 и 40 mass\% хлорида аммония (ГА20, ГА40).

Для сравнения было проведено исследование структуры и свойств порошка, полученного методом осаждения и содержащего 40 mass\% хлорида аммония, который дополнительно обрабатывали при $T=300^{\circ} \mathrm{C}$ в течение 30 min (образец ГА).

Фазовый анализ и расчет параметров кристаллической структуры образцов проводили методом рентгеновской дифракции на установке D2 Phaser (Bruker, Germany) использовали $\mathrm{Cu} K_{\alpha}$-излучение. Обработка данных была выполнена с помощью программного обеспечения Topas 5.0 (Bruker). Размеры кристаллитов рассчитывали по интегральной ширине рефрексов с помощью программного обеспечения MAUD.

Пористую структуру и величину удельной поверхности определяли сорбционными методами, измерения проводили на газоадсорбционном порозиметре NOVA-1200e, США.

Термогравиметрический анализ (ТГА) образцов ГА был проведен на установке 209 F1 NETZSCH, Германия, в диапазоне температур от 30 до $800^{\circ} \mathrm{C}$ при скорости нагрева $10 \mathrm{deg} / \mathrm{min}$ в инертной среде (аргон). Расход инертного газа составлял $40 \mathrm{ml} / \mathrm{min}$.

Частицы ГА, ГА20 и ГА40 выдерживали в питательной среде $\alpha$-MEM (Lonza, США) с добавлением $10 \%$ сыворотки крупного рогатого скота (HyClone, США) в течение 1 суток. Концентрация частиц ГА в питательной среде составила $0.01 \mathrm{~g} / \mathrm{ml}$. Ранее другими авторами было продемонстрировано, что даже незначительное содержание ГА, которое составляло не более $1 \%$ или $0.01 \mathrm{mg} / \mathrm{ml}$, увеличивает остеогенный потенциал клеток [9]. Пролиферацию СК in vitro изучали в системе
xCELLigenceRealTimeCellularAnalysis (RTCA). Первоначально измеряли фоновое сопротивление $100 \mu 1$ питательной среды в лунках. $100 \mu 1$ суспензии, содержащей $5 \cdot 10^{3}$ клеток, вносили в лунки, и с помощью RTCAсистемы оценивали пролиферацию. После культивирования в течение 1 суток питательную среду удаляли, и в лунки с клетками добавляли $100 \mu 1$ питательной среды после инкубирования с частицами ГА. Клетки, культивируемые в питательной среде без инкубирования с частицами, служили положительным контролем. Изменения в сопротивлении, обозначенные как клеточный индекс (КИ), рассчитывали автоматически как СК, которые взаимодействуют с электродами $E$-планшетов.

\section{2. Обсуждение результатов}

На рис. 1 приведены рентгеновские дифрактограммы образцов ГА, ГА 20 и ГА40. Из приведенных данных следует, оба образца синтетического ГА, не подвергнутые термической обработке, содержат хлорид аммония в виде второй фазы. Образец, обработанный при $T=300^{\circ} \mathrm{C}$, содержит только кристаллы ГА.

Количественный фазовый анализ показал, что концентрация хлорида аммония в образце ГА20 составляет 21.5 и 38.6 mass\% в образце ГА 40. Узкие дифракционные максимумы на рентгенограмме образца ГА свидетельствуют о более высокой кристалличности (больших размерах кристаллитов, меньшей их дефектности) по сравнению с образцами, содержащими $\mathrm{NH}_{4} \mathrm{Cl}$. Средний размер кристаллитов в ГА составляет $24 \mathrm{~nm}$, для образца ГА20 это значение несколько ниже и равно $18 \mathrm{~nm}$, аналогичная величина для ГА 40 составляет $15 \mathrm{~nm}$.

Термические свойства образцов ГА, ГА20 и ГА40 исследовали методом ТГА. На рис. 2 приведены зависимости потери массы от температуры в интегральном и дифференциальном виде. Видно, что для образцов ГА20 и ГА40 при $T=240-250^{\circ} \mathrm{C}$ наблюдается интенсивная потеря массы, величина которой для ГА40 составляет



Рис. 1. Рентгеновские дифрактограммы порошков ГА, ГА20 и ГА40 (кривые 1-3). Вертикальные линии соответствуют дифракционным максимумам в соответствии с ICDD № 24-33 и № 7-7 для гидроксиапатита и хлорида аммония соответственно. 


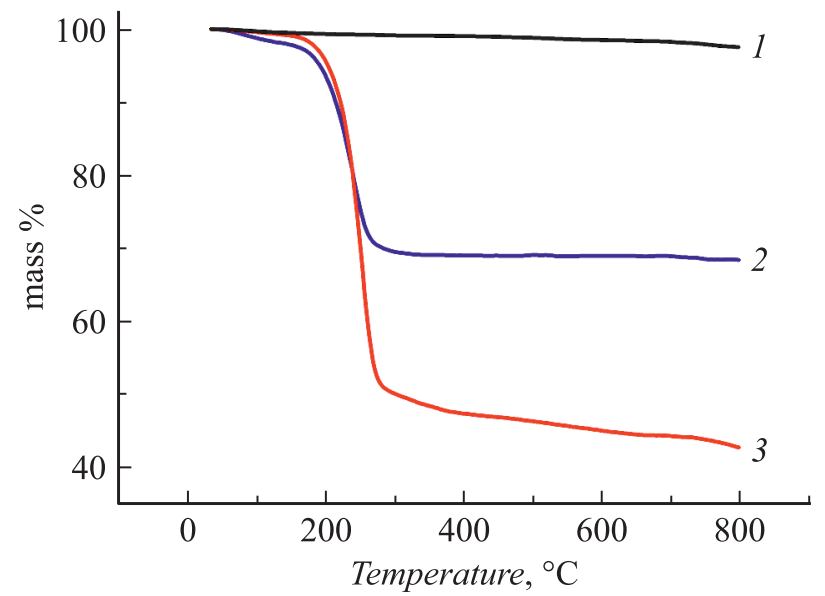

Рис. 2. ТГА кривые для $1-$ ГА, $2-$ ГА20, $3-$ ГА 40.

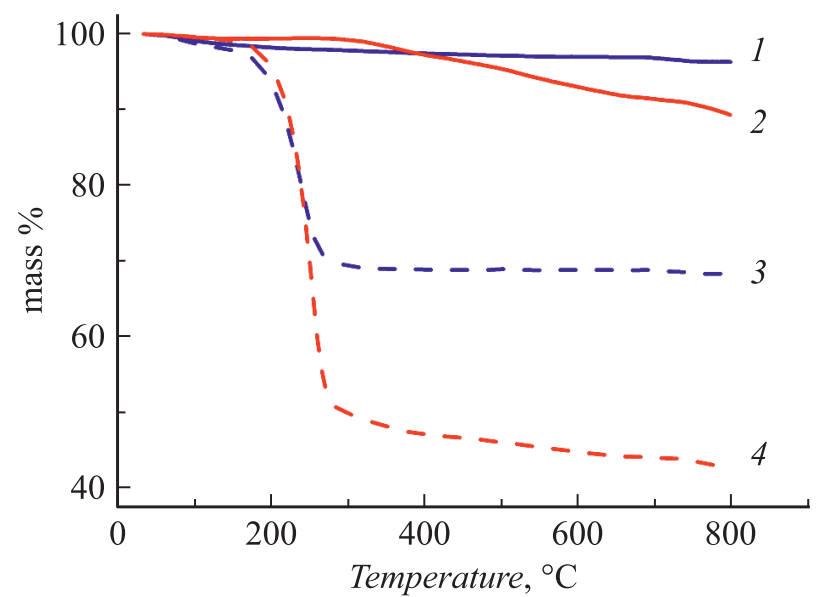

Рис. 3. Результаты термического анализа образцов ГА20 и ГА40: 1 - ГА20 после обжига, 2 - ГА40 после обжига, 3 ГА20 исходный, $4-$ ГА40 исходный.

около $50 \%$, а для ГА20 30\%. При этом потери массы для ГА в этом температурном диапазоне не наблюдается. Отметим, что по данным рентгенофазового анализа образцы ГА20 и ГА40 содержат в значительном количестве кристаллы хлорида аммония.

Известно [10], что температура возгонки кристаллов хлорида аммония составляет $337^{\circ} \mathrm{C}$. Процесс возгонки сопровождается образованием аммиака $\left(\mathrm{NH}_{3}\right)$ и хлористого водорода $(\mathrm{HCl})$, которые при снижении температуры способны вновь соединяться в хлорид аммония. Отметим, что температура плавления кристаллических веществ существенно зависит от таких параметров, как размеры кристаллов, наличие примесей, пористость и др. Исходя из этого, можно предположить, что значительная потеря массы при $T=250^{\circ} \mathrm{C}$ связана с разложением кристаллов хлористого аммония, входящего в состав ГА20 и ГА40. В пользу этого свидетельствует полное отсутствие потери массы в этом температурном
Объемная пористость и удельная поверхность образцов ГА, ГА20 и ГА 40

\begin{tabular}{c|c|c}
\hline Образец & $\begin{array}{c}\text { Объем пор, } \\
\mathrm{cm}^{3} / \mathrm{g}\end{array}$ & $\begin{array}{c}\text { Удельная поверхность, } \\
\mathrm{m}^{2} / \mathrm{g}\end{array}$ \\
\hline ГА20 & 0.152 & 57.789 \\
ГА40 & 0.055 & 14.492 \\
ГА & 0.050 & 13.616
\end{tabular}

диапазоне для ГА, полученного из ГА40 и термообработанного при $300^{\circ} \mathrm{C}$.

Справедливость высказанного предположения подтверждается результатами экспериментов по термообработке при $T=300^{\circ} \mathrm{C}$ образцов синтетического ГА. На рис. 3 приведены ТГА кривые для образцов ГА20 и ГА40 до и после термообработки в течение $30 \mathrm{~min}$ при $T=300^{\circ} \mathrm{C}$. Видно, что для исходных образцов наблюдается существенная потеря массы при $T=220-250^{\circ} \mathrm{C}$. Образцы, подвергшиеся дополнительной высокотемпературной обработке $\left(300^{\circ} \mathrm{C}\right)$, обладают термостабильностью в широком температурном диапазоне. Эти данные свидетельствуют в пользу удаления хлорида аммония в процессе термообработки при $T=300^{\circ} \mathrm{C}$.

Отметим, что разложение хлорида аммония, выделение аммиака и хлористого водорода происходит при температурах, которые для получения материалов для тканевой инженерии, а также в клеточных технологиях не используют.

Наночастицы ГА используют в качестве наполнителей в композиционных материалах. Композиционные волокна, пленки и губки в последнее время находят применение как матрицы для тканевой инженерии. Взаимодействие полимерной матрицы с наполнителем в значительной степени зависит от его удельной поверхности. Пористая структура, величина удельной поверхности определяют реакционную способность материала, скорость протекания химических и биологических процессов в активных средах. Последнее важно при прогнозировании резорбции наночастиц ГА и материалов, в состав которых они входят после имплантации.

В таблице приведены значения объемной пористости и величины удельной поверхности образцов ГА, ГА20 и ГА 40.

Из приведенных данных видно, что наибольшим объемом пор и величиной удельной поверхности обладает образец синтетического ГА20. Параметры пористой структуры образца ГА40 близки к аналогичным значениям ГА, подвергнутого термической обработке. Можно предположить, что кристаллы хлорида аммония располагаются в порах наночастиц. Поэтому пористость образца ГА40 ниже, чем аналогичная величина образца, содержащего меньшее количество фазы $\mathrm{NH}_{4} \mathrm{Cl}$. Уменьшение пористости и удельной поверхности термообработанного образца, видимо, связано с повышением его кристалличности в процессе отжига. Как показали 


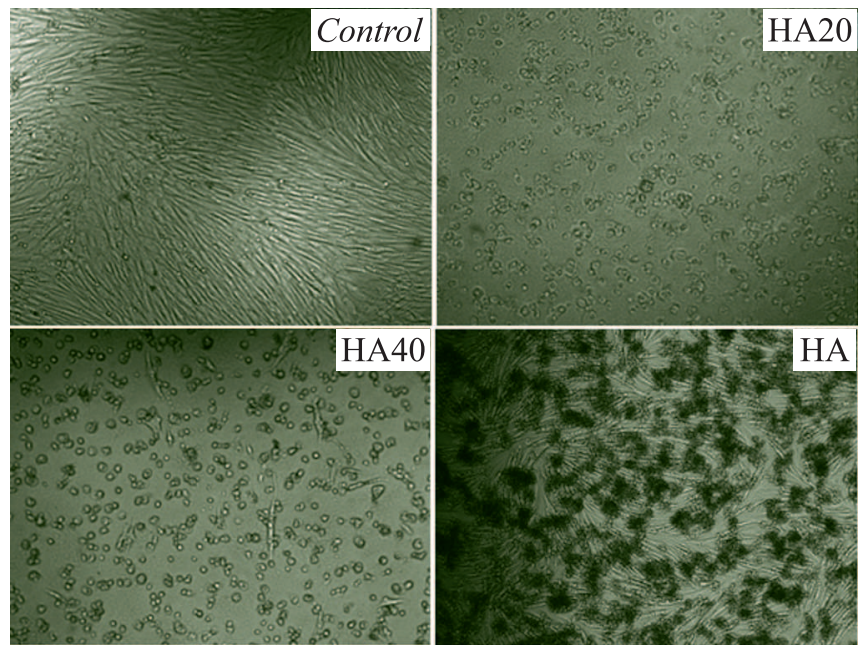

Pис. 4. Световая микроскопия СК после 1 недели культивирования в жидких средах, полученных после культивирования аналогичных клеток в присутствии частиц ГА, ГА20 и ГА40; увеличение $10 \times$.

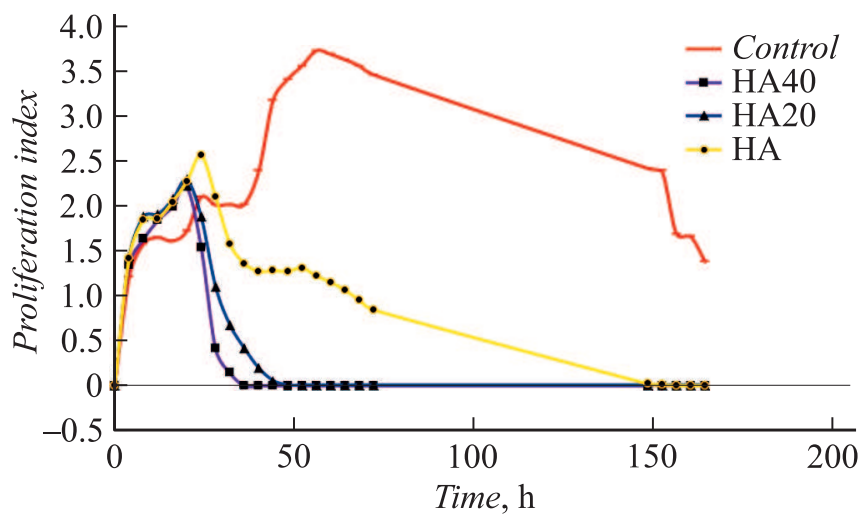

Рис. 5. Изменение индекса пролиферации стромальных клеток в зависимости от времени культивирования в присутствии питательной среды после инкубирования с частицами ГА, ГА20, ГА40; контроль - клетки после культивирования в среде без предварительного инкубирования с частицами ГА.

результаты рентгеноструктурного анализа, этот образец отличается повышенными размерами кристаллитов, меньшей их дефектностью.

Результаты исследования пролиферации СК в культуральных средах, полученных после сокультивирования аналогичных клеток и частиц с разным содержанием хлорида аммония, приведены на рис. 4. Видно, что в контрольном образце СК образовали полный монослой. Клетки имеют веретенообразную форму и расположены по гиперболическим траекториям. После культивировании клеток в жидких средах, полученных после сокультивирования с ГА20 и ГА40, большинство клеток сохраняют округлую форму. Отметим, что в эксперименте по пролиферации СК в среде с меньшим содержанием хлористого аммония (после сокультивирования СК и частиц ГА20), наряду с клетками округлой формы видны клетки вытянутой формы, характерной для контрольного образца. Морфология клеток в присутствии питательной среды после инкубирования частиц ГА, обработанных при высокой температуре, близка к морфологии клеток в контрольном образце. Клетки имеют вытянутую веретеновидную форму.

Округлая форма клеток, отсутствие веретенообразных клеток при культивировании в среде, полученной после сокультивирования клеток с частицами ГА20 и ГА40, свидетельствуют о ее негативном влиянии на клеточные процессы. Можно предположить, что в процессе сокультивирования клеток и наночастиц в биологически активной культуральной среде происходит частичный гидролиз хлорида аммония в соответствии с уравнением

$$
\mathrm{NH}_{4}^{+}+\mathrm{Cl}^{-}+\mathrm{HOH} \rightleftarrows \mathrm{NH}_{4} \mathrm{OH}+\mathrm{H}^{+}+\mathrm{Cl} .
$$

$\mathrm{NH}_{4} \mathrm{Cl}$ используют в гистологии в качестве красителя тканевого материала, гематологии - для лизиса эритроцитов крови, в цитологии - для сортировки клеток, т.е. это вещество взаимодействует с клетками, способствует их разделению для последующего анализа. Также известно, что ионы аммония синтезируются некоторыми бактериями в организме и участвуют в физиологических процессах [11]. Однако, как показали результаты проведенных исследований, наличие в культуральной среде достаточно большого количества $\mathrm{NH}_{4} \mathrm{Cl}$ препятствует распластыванию клеток, существенно снижает их пролиферативную активность.

Это подтверждает количественная оценка индекса пролиферации СК (рис. 5). Видно, что по истечении 1 суток при добавлении питательной среды после инкубирования с частицами ГА, индекс пролиферации клеток существенно снижается по сравнению с контролем. Причем чем больше хлористого аммония в образце, тем ниже индекс пролиферации. Отжиг образца ГА приводит к уменьшению количества хлористого аммония, и к увеличению пролиферативной активности СК. Хотя и этот образец уступает контролю, но в меньшей степени по сравнению с образцами ГА20 и ГА 40.

\section{Выводы}

Получены наночастицы, содержащие ГА и хлорид аммония в различном соотношении. Показано, что разложение кристаллов хлорида аммония происходит в интервале температур $220-270^{\circ} \mathrm{C}$. Наличие хлорида аммония в культуральной среде существенно снижает пролиферативную активность стволовых клеток. Термическая обработка наночастиц при $T=300^{\circ} \mathrm{C}$ приводит к снижению их негативного влияния на пролиферативную активность стромальных клеток, существенному повышению биосовместимости. 


\section{Благодарности}

Авторы благодарят Ресурсный центр „Рентгенодифракционные методы исследования“ Научного парка СПбГУ за проведение исследований по рентгеноструктурному анализу.

\section{Финансирование работы}

Работа выполнена при поддержке Российского научного фонда, проект № 19-73-30003.

\section{Конфликт интересов}

Авторы заявляют, что у них нет конфликта интересов.

\section{Список литературы}

[1] Dobrovolskaya I.P., Yudin V.E., Popryadukhin P.V., Ivan'kova E.M. St. Petersburg: Mediapapir, 2018. 232 p.

[2] Parisi M., Stoller M., Chianese A. // Chem. Eng. Trans. 2011. Vol. 24. P. 211-216.

[3] Dobrovol'skaya I.P., Tsarev N.S., Osmolovskaya O.M., Kasatkin I.A., Ivan'kova E.M., Popova E.N., Yudin V.E. // Russ. J. Appl. Chem. 2018. Vol. 91. N 3. P. 368-374. DOI: $10.1134 / \mathrm{S} 1070427218030035$

[4] Dorozhkin S. // Materials. 2009. Vol. 2. N 2. P. 399-498. DOI:10.3390/ma2020399

[5] Šupová M. // J. Nanoscience Nanotechnol. 2014. Vol. 14. N 1. P. 546-563. DOI: 10.1166/jnn.2014.8895

[6] Sadat-Shojai M., Khorasani M.T., Dinpanah-Khoshdargi E., Jamshidi A. // Actabiomater. 2013. Vol. 9. N 8. P. 7591-7621. DOI:10.1016/j.actbio.2013.04.012

[7] Lin K., Wu C., Chang J. // Actabiomater. 2014. Vol. 10. N 10. P. 4071-4102. DOI: 10.1016/j.actbio.2014.06.017

[8] Caprariis B., Chianese A., Stoller M., Verdone N. // Hydroxyapatite-Advances in Composite Nanomaterials, Biomedical Applications and Its Technological Facets. IntechOpen. 2018. DOI: 10.5772/intechopen.71775

[9] Carles-Carner M., Saleh L.S., Bryant S.J. // Biomed. Mater. 2018. Vol. 13. N 4. P. 045009.

DOI: $10.1088 / 1748-605 X / a a b b 31$

[10] Galston A.W. Biological Chemistry Henry R. Mahler Eugene H. Cordes. 1967.

[11] Matsui T., Matsukawa Y., Sakai T., Nakamura K., Aoike A., Kawai K. // Dig. Dis. Sci. 1997. Jul. Vol. 42. N 7. P. 1394-9. DOI: 10.1023/A:1018837920769 